\title{
Reseña de: Prieto Borrego, Lucía. Mujer, moral y franquismo. Del velo al bikini. Málaga: UMA Editorial Colección, Atenea Estudios de Género, 2018.
}

\author{
SERGIO BLANCO FAJARDO \\ Universidad de Málaga
}

Las investigaciones actuales sobre el franquismo y las mujeres vienen centrando el debate, entre otros aspectos, en la reinterpretación de las agencias femeninas desarrolladas en el seno de instituciones como Sección Femenina y Acción Católica, en las disidencias internas de los discursos producidos o en las formas de represión y las resistencias manifestadas. Al calor de esta sinergia que ha servido de acicate para la producción histórica reciente, encontramos los trabajos de diversas autoras (Blasco, Cenarro, Morcillo, Moreno y Ofer), un pequeño ejemplo de otros tantos estudios, entre los que se inserta la presente obra que analiza en profundidad la institución del Patronato de la Mujer.

En el trabajo de Lucía Prieto se utilizan conceptos medulares que explican los discursos, las experiencias y prácticas sociales en relación con la feminidad; en primer lugar, la moral, que sirvió de sustrato formativo. La moral de las mujeres baremó el estatus social familiar y basculó en un sentido dispar, propiciando la aseveración de una doble moral social y sexual, que explica en buena medida la propia existencia de la institución presidida por Carmen Polo y las estrategias formuladas al uso. Otro elemento que no pasa desapercibido es la división entre lo público y lo privado. Las celadoras y visitadoras y las denuncias sociales contextualizan y legitiman la intervención estatal, no solo dirigida a las prostitutas, sino a todas las mujeres que asumían actividades impropias, en gran medida relacionadas con el peligro que la esfera pública

Los contenidos de la revista se publican bajo una licencia de Creative Commons Reconocimiento 4.0 Internacional (CC BY 4.0)

Feminismo/s 33, junio 2019, pp. 355-359 
prescribía para ellas. En último lugar, se vislumbran las redes de poder que creó el propio Patronato, entre otras instituciones, a la hora de reformular el control social ejercido, de forma castradora y predatoria, sobre los cuerpos, las mentalidades y las subjetividades femeninas. Esta perspectiva analítica descubre una serie de elementos que conformaron un sistema pragmático orientado a la represión y el control impuesto por las políticas del régimen.

El libro se encuentra dividido en dos grandes bloques que abarcan la totalidad de la dictadura franquista. El primero de ellos, dedicado a la cuestión central, el Patronato de la Mujer (1941), está orientado hacia una teorización del objeto de estudio y el desarrollo de la institución desde una perspectiva general. En segundo lugar, introduce el análisis del caso malagueño, a modo de ejemplo, para profundizar en los métodos de actuación y los mecanismos que operaron en el seno del Patronato.

El primer bloque se nutre de seis capítulos. El primero de ellos introduce la base teórica y conceptual que apuntalaba la institución en torno a las teorías filosóficas de la Antigüedad y la escolástica medieval. La franja de pensamiento en la que coinciden Aristóteles y Tomás de Aquino es la supuesta inferioridad femenina y el concepto pecaminoso insertado en el sujeto mujer. En este último se basaban las ideas del régimen sobre la prostitución, explicando su existencia como un «mal menor» que contenía a otros mayores, al menos hasta 1956. No obstante, desde la vertiente católica, uno de los principales pilares del régimen y de su moralidad, las voces de los jesuitas clamaban en contra de la prostitución reglada. La contradicción se pretendió resolver, precisamente, con la creación del Patronato, cuya misión, ponerse al servicio de la regeneración moral de las mujeres, encubría esta estridente paradoja. Desde una posición pretendidamente científica, López Ibor y Vallejo Nájera argumentaron en favor de la susceptibilidad femenina al pecado, y por tanto, de la necesidad profiláctica asociada a la regeneración racial. Este es concretamente el tema que perfila el segundo capítulo, los fines y actuaciones del Patronato, a partir de su carácter redentor, regenerador y represor, en constante vigilancia de cualquier actitud disidente. En este recorrido se esbozan las fuentes utilizadas por la autora: los informes de las Juntas de Patronato, la Liga Española Contra la Pública Inmoralidad y las fuentes policiales sobre las denuncias al uso establecidas. Uno de los aciertos que se desprenden de la obra, aunque focalice un caso local, la Junta de Patronato malagueña, es la

Feminismo/s 33, junio 2019, pp. 355-359 
contextualización general de la institución franquista, y en correlación con ellos, la presentación de múltiples casos y el uso de fuentes primarias que abarcan dispares emplazamientos a lo largo de la geografía española. De este modo, el libro se convierte en un referente para el estudio de la casuística de forma transversal, sin que este enfoque signifique reducir la mirada hacia el localismo, al contrario, el análisis de este caso singular sirve para profundizar de forma más pormenorizada en su estructura y funcionalidad.

La evolución que sufrió el Patronato a lo largo de la dictadura, a medida que sus objetivos principales cambiaban hacia la reeducación y la rehabilitación como vehículo de reinserción social de la mujer prostituida, no logró que se desprendiera de la pátina religiosa que formulaba su actuación con métodos piadosos y cristianos. Más bien, señaló el hermetismo de esta institución y la imposibilidad de amoldarse a los cambios que preconizaba el modelo desarrollista, en unos años en los que sus esfuerzos se dirigieron a combatir el peligro moral que protagonizó el éxodo femenino del campo a la ciudad. A estas temáticas se circunscriben los últimos capítulos que cierran el bloque.

El estudio del caso malagueño transita las zonas subterráneas del franquismo: la prostitución de menores, la actuación de madres y padres que inducían a sus hijas a vender sus cuerpos por raciones de comida o la presencia de «seductores» que quebraron la vida de decenas de jóvenes para luego abandonarlas a una suerte aciaga. En los casos seleccionados se explicitan también las denuncias convenidas para conseguir algún tipo de ayuda económica y, sobre todo, el internamiento preventivo de las jóvenes en situaciones de gran riesgo por la pérdida de su moralidad. La naturaleza plural de las denuncias y las actuaciones ponen en relieve, en primer lugar, el entramado de las relaciones de género, incidiendo las denuncias en las mujeres y exculpando o suavizando la implicación masculina. En segundo lugar, se manifiesta el componente de algunos centros, dedicados casi en su totalidad a la reclusión de jóvenes de familias acomodadas, como mecanismo de protección de la honra familiar y de higiene social. El Patronato de la Mujer se convierte en un rico ejemplo para estudiar la instrumentalización de la honestidad femenina y de la moral católica para regir todos los aspectos de la vida de las mujeres. La reinterpretación de personajes históricos como mitos nacionalistas -es el caso de Teresa de Jesús o Isabel la Católica-, que fueron deformados en aras de las necesidades del régimen, incidió en la construcción de un modelo de

Feminismo/s 33, junio 2019, pp. 355-359 
feminidad normativo que se defendió e inculcó en la programación de los centros de mujeres.

El poder y la expansión de las redes asistenciales y tutelares demuestran las dimensiones del control social, la represión y las violencias que el régimen utilizó contra las mujeres. Este aspecto invita a reflexionar sobre el concepto de «patriarcado fascista» en relación con la Italia de Mussolini (de Grazia 158-192). Sin pretender extrapolar esta noción, la obra invita a pensar sobre la diversidad de mecanismos que operaron en la construcción de la «perfecta ama de casa», la reconstrucción del modelo de mujer dependiente y sumisa, la recristianización de la sociedad y la consideración del cuerpo de las mujeres como una llamada al pecado eterno y la abnegación convertida en referente de la actitud y el pensamiento. Todo ello desembocará en un esquema hermético de lo femenino. Es cierto que la realidad desprendió matices, disidencias y resistencias, sobre todo, en la segunda etapa de la dictadura, pero no lo es menos el afirmar que la dictadura fue una sociedad gris para las mujeres. En este marco histórico se aprecian penumbras y claroscuros que ponen en evidencia el éxito del proyecto adoctrinador femenino basado en la matriz totalitaria del aparato de gobierno y de la ideología versada en el nacionalcatolicismo a la hora de componer el ideal de «mujer española».

En definitiva, la presente obra a la vez que define las experiencias que giraron en torno al Patronato de la Mujer, invita por su calidad de matices a repensar la situación de las mujeres durante el franquismo, como víctimas y sujetos adoctrinados, pero también a repensar las agencias políticas y sociales que usaron la institución a su conveniencia, de modo revanchista o protector, desde una perspectiva de clase. Por último, hay que destacar el valor historiográfico del libro de Lucía Prieto, que pone de relieve la necesidad de incorporar al debate -en el marco de la historia de género y la dictadura franquista-, las políticas y diálogos internos de Sección Femenina y Acción Católica, y el análisis de las instituciones que operaron en la conceptualización, el adoctrinamiento, el control y la represión de las mujeres. Sin duda esta perspectiva enriquecerá y puntualizará el relato histórico sobre la dictadura. 


\section{REFERENCIAS BIBLIOGRÁFICAS}

Blasco Herranz, Inmaculada. «Género y nación durante el franquismo». Imaginarios y representaciones de España durante el franquismo. Eds. Stéphane Michonneau y Xosé M. Núñez Seixas. Madrid: Casa de Velázquez, 2014. 49-71.

Cenarro, Ángela. «La Falange es un modo de ser (mujer): discursos e identidades de género en las publicaciones de la Sección Femenina (1938-1945)». Historia y Política 37 (2017): 91-120.

De Grazia, Victoria. «Patriarcado fascista: las italianas bajo el gobierno de Mussolini, 1922-1940». Historia de las mujeres en Occidente. Vol. 5. Eds. Georges Duby y Michelle Perrot. Madrid: siglo XX-Taurus, 2000. 158-192.

Morcillo Gómez, Aurora. En cuerpo y alma. Ser mujer en tiempos de Franco. Madrid: Siglo XXI, 2015.

Moreno Seco, Mónica. «Mujeres en la Acción Católica y el Opus Dei. Identidades de género y culturas políticas en el catolicismo de los años sesenta». Historia y política 28 (2012):167-194.

Ofer, Inbal. «A 'new'woman for a 'new' Spain: the Sección Femenina de la Falange and the image of the national syndicalist woman». European History Quarterly 39.4 (2009): 583-605. 